\title{
ASSESSMENT OF LONG-TERM LEFT INTERNAL THORACIC ARTERY GRAFT PATENCY BY EXERCISE DOPPLER ECHOCARDIOGRAPHY
}

Yuki Yoshida, MT, ${ }^{\text {a }}$ Masatoshi Fujita, MD, ${ }^{\mathrm{b}}$ Yasuki Kihara, MD, ${ }^{\mathrm{b}}$ Shigeru Kubo, MT, ${ }^{\mathrm{a}}$ Terumitsu Tanaka, MD, ${ }^{\mathrm{c}}$ Tomoyuki Iwase, MD, ${ }^{\mathrm{c}}$ Shun-ichi Tamaki, MD, ${ }^{\mathrm{c}}$ Tatsuro Sato, MD,${ }^{\mathrm{d}}$ Chang-Hee Park, MD, ${ }^{\mathrm{d}}$ and Ario Yamazato, MD, ${ }^{\mathrm{d}}$ Kyoto, Japan

Internal thoracic artery grafting is preferable to grafting with saphenous veins because of the higher long-term patency rate. ${ }^{1}$ Coronary arteriography is still a gold standard for left internal thoracic artery (LITA) graft patency. However, the angiographic approach is limited in evaluating physiologic response to increased myocardial oxygen demand and in repeated investigations during the longterm follow-up period. Doppler echocardiography is reported to be a reliable method to noninvasively assess the LITA flow pattern. ${ }^{2-4}$ However, to our best knowledge, there is no report on LITA graft flow characteristics during exercise. In the present study, therefore, we hypothesized that Doppler echocardiography during exercise would provide more precise information about patency of the LITA graft during the long follow-up period.

Methods. Among 38 consecutive cases of coronary artery bypass grafting with the LITA to the left anterior descending coronary artery (LAD), exercise Doppler echocardiography was performed in 22 patients $(20$ men, 2 women, $60 \pm 7$ [standard deviation] years) who had not had a previous anterior myocardial infarction and had $90 \%$ to $100 \%$ diameter stenosis in the LAD proximal to the anastomotic site. These patients were selected to be studied, and after their Doppler study they all underwent

From the Departments of Clinical Laboratory, ${ }^{\mathrm{a}}$ Cardiology, ${ }^{\mathrm{c}}$ and Cardiovascular Surgery, ${ }^{\mathrm{d}}$ Takeda Hospital, and College of Medical Technology, Kyoto University, ${ }^{b}$ Kyoto, Japan.

Received for publication July 18, 1997; accepted for publication Oct. 7, 1997.

Address for reprints: Masatoshi Fujita, M.D., Professor, College of Medical Technology, Kyoto University, 53 Kawaharacho, Shogoin, Sakyo-ku, Kyoto, 606-01, Japan.

J Thorac Cardiovasc Surg 1998;115:954-6

Copyright (c) 1998 by Mosby, Inc.

0022-5223/98 $\$ 5.00+0 \quad \mathbf{1 2 / 5 4 / 8 6 7 1 5}$ a second coronary angiography. The time interval between the operation and the Doppler study was $20.9 \pm 7.0$ days.

Supine bicycle exercise testing was conducted at a constant workload of $25 \mathrm{~W}$ until either chest pain or leg fatigue appeared. After a 24-hour withdrawal of all medications, Doppler echocardiographic studies were performed with a Toshiba SSA-260A echocardiograph with a $5 \mathrm{MHz}$ transducer. The transducer was positioned at the left supraclavicular fossa, the ultrasonic beam was directed toward the caudal site from the transducer, and the LITA graft was observed on the two-dimensional echocardiogram. ${ }^{3}$ The sample volume was placed on the graft, and graft blood flow was detected by means of pulsedwave Doppler echocardiography. Doppler signals were recorded for 30 seconds at rest and for 30 seconds immediately after the cessation of exercise on a videotape for later analysis.

On the basis of the angiographic data, 22 patients were divided into two groups: group A, 15 patients with a patent LITA graft $(<25 \%$ diameter stenosis); group B, seven patients with a severely stenosed LITA graft $(75 \%$ to $99 \%$ diameter stenosis) at the site of the anastomosis with the LAD. No stenosis was found in the proximal site of the LITA graft where flow velocities were measured. Ten of 15 patients in group A were restudied 10 months after the operation to evaluate the long-term LITA graft patency.

Results. In all patients, optimal Doppler signal recordings were obtained at rest and during exercise. There were no significant differences in the diastolic/systolic peak velocity ratio and diastolic fraction of time-velocity integral at rest between groups A and B (Fig. 1). The exercise to rest ratio of mean diastolic velocity (the index of LITA flow reserve) was $2.03 \pm 0.48$ in group A, being significantly higher than $1.26 \pm 0.20$ in group $\mathrm{B}(p<0.01)$ (Fig. $2)$. There were no significant differences in pressure-rate 

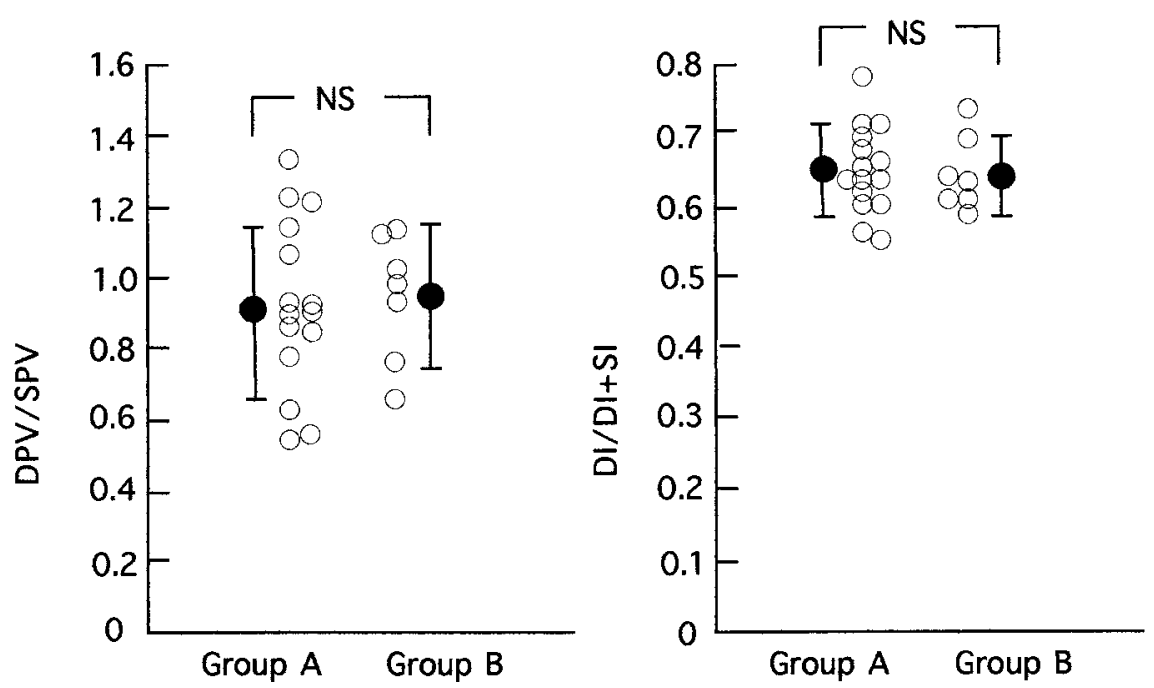

Fig. 1. Comparison of resting velocity parameters between groups A and B. DI, Diastolic time-velocity integral; $D P V$, diastolic peak velocity; $S I$, systolic time-velocity integral; $S P V$, systolic peak velocity.

products between groups A and B either at rest (9,642 \pm 1,921 vs $9,645 \pm 1,102 \mathrm{~mm} \mathrm{Hg} \cdot$ beats/min) or during exercise $(17,228 \pm 3,494$ vs $16,405 \pm 1,331 \mathrm{~mm} \mathrm{Hg} \cdot$ beats/ $\min )$.

Of 15 group A patients with a patent LITA graft, 10 patients had a total occlusion of the LAD, and the remaining five patients had $90 \%$ to $99 \%$ stenosis of the LAD. There were no significant differences in the diastolic/systolic peak velocity ratio and diastolic fraction of time-velocity integral at rest, and the index of LITA flow reserve between patients with a total occlusion and severe stenosis of the LAD.

Follow-up study was conducted in 10 of 15 patients in group $\mathrm{A}$ at a mean of $9.9 \pm 4.0$ months after bypass grafting. In one patient, follow-up study was performed 4 months later, because a follow-up treadmill stress test had revealed the significant ST-segment depression without chest pain. Stress myocardial ${ }^{201} \mathrm{Tl}$ scintigraphy had also revealed a reversible defect in the anteroseptal wall. In this patient, the index of LITA flow reserve was decreased from 2.00 to 1.14 at the follow-up study. Coronary angiography disclosed a 99\% LITA graft stenosis at the site of anastomosis with the LAD. The patient was then successfully treated with percutaneous transluminal coronary angioplasty. The index remained unchanged in the remaining nine patients during the follow-up period.

Discussion. Our study demonstrated that it is possible to noninvasively evaluate the LITA graft flow during exercise by Doppler echocardiography. This method appears to be very useful for evaluation of the LITA graft patency and can be performed repeatedly during the follow-up period. Although angiographic follow-up remains a gold standard for assessing the condition of the LITA graft, it is not suitable for repetitive assessment. Exercise Doppler echocardiography can be applied to ambulatory patients to determine the indication of catheterization as a noninvasive diagnostic test. However, the response of the LITA graft flow to exercise may be

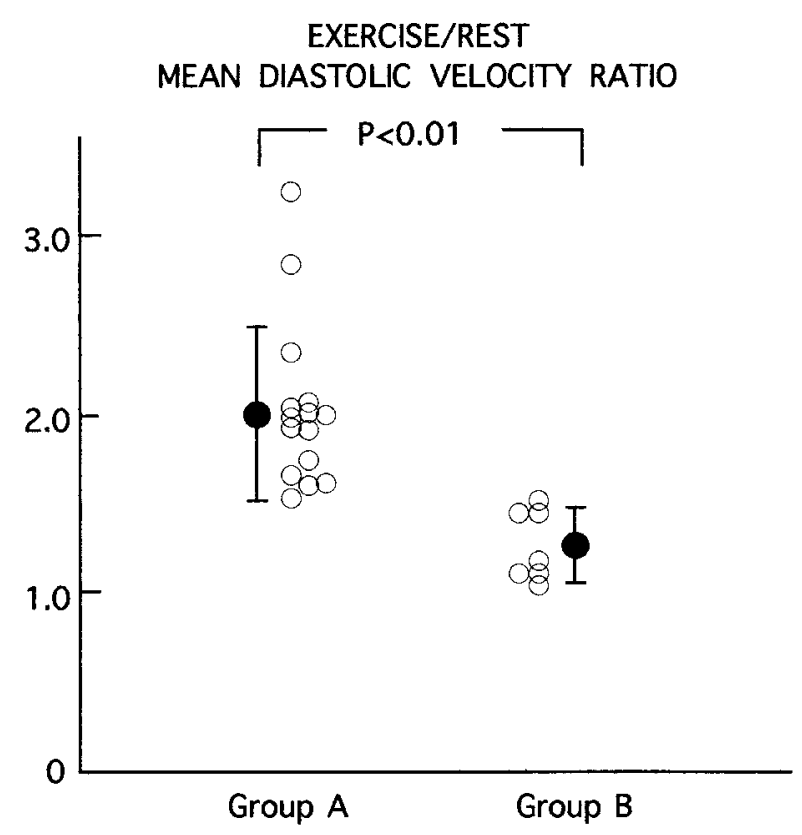

Fig. 2. Comparison of exercise/rest mean diastolic velocity ratio between groups $\mathrm{A}$ and $\mathrm{B}$.

variable, because the size of perfusion area, myocardial functional status, the degree of LAD stenosis, and the number of the remnant side branches of the LITA are different among patients.

In our study, no differences were found in the diastolic/ systolic peak velocity ratio and the diastolic fraction of time-velocity integral in the resting state between patients with and without severe LITA graft stenosis. These results indicate that the diastolic flow is maintained at rest even in patients with severe graft stenosis of LITA. With the 
increase in the pressure-rate products by exercise, a statistically significant difference $(p<0.01)$ was observed in the index of LITA flow reserve between groups A and B. This finding is consistent with previous observations regarding the coronary flow reserve assessed with a vasodilator. $^{5}$

In conclusion, exercise Doppler echocardiography enabled us to make a noninvasive evaluation of the LITA graft patency. This method was useful for routine postoperative follow-up of patients with LITA grafts.

\section{REFERENCES}

1. Loop FD, Lytle BW, Cosgrove DM, et al. Influence of the internal mammary artery graft on 10-year survival and other cardiac events. N Engl J Med 1986;314:1-6.
2. Canver CC, Fiedler RC, Hoover EL, Ricotta JJ, Mentzer RM. Noninvasive assessment of internal thoracic artery for reoperative coronary artery surgery. J Cardiovasc Surg 1992;33: 534-7.

3. Takagi T, Yoshikawa J, Yoshida K, Akasaka T. Noninvasive assessment of left internal mammary artery graft patency using duplex Doppler echocardiography from supraclavicular fossa. J Am Coll Cardiol 1993;22:1647-52.

4. Nasu M, Akasaka T, Okazaki T, et al. Postoperative flow characteristics of left internal thoracic artery grafts. Ann Thorac Surg 1995;59:154-62.

5. Iliceto S, Marangelli V, Memmola C, Rizzon P. Transesophageal Doppler echocardiography: evaluation of coronary blood flow velocity in baseline condition and during dipyridamole induced coronary vasodilatation. Circulation 1991;83: $61-9$. 